\title{
High-Temperature Performance and Multiscale Damage Mechanisms of Hollow Cellulose Fiber-Reinforced Concrete
}

\author{
Liping Guo, ${ }^{1,2,3}$ Wenxiao Zhang, ${ }^{1,4}$ Wei Sun, ${ }^{1,2,3}$ Bo Chen, ${ }^{4}$ and Yafan Liu ${ }^{5}$ \\ ${ }^{1}$ School of Materials Science and Engineering, Southeast University, Nanjing 211189, China \\ ${ }^{2}$ Jiangsu Key Laboratory of Construction Materials, Nanjing 211189, China \\ ${ }^{3}$ Collaborative Innovation Center for Advanced Civil Engineering Materials, Nanjing 211189, China \\ ${ }^{4}$ State Key Laboratory of Hydrology, Water Resources and Hydraulic Engineering, Nanjing Hydraulic Research Institute, \\ Nanjing 210029, China \\ ${ }^{5}$ School of Civil Engineering, Southeast University, Nanjing 211189, China
}

Correspondence should be addressed to Liping Guo; guoliping691@163.com

Received 13 November 2015; Accepted 27 December 2015

Academic Editor: Ying Li

Copyright (C) 2016 Liping Guo et al. This is an open access article distributed under the Creative Commons Attribution License, which permits unrestricted use, distribution, and reproduction in any medium, provided the original work is properly cited.

\begin{abstract}
Spalling resistance properties and their damage mechanisms under high temperatures are studied in hollow cellulose fiberreinforced concrete (CFRC) used in tunnel structures. Measurements of mass loss, relative dynamic elastic modulus, compressive strength, and splitting tensile strength of CFRC held under high temperatures $\left(300,600,800\right.$, and $\left.1050^{\circ} \mathrm{C}\right)$ for periods of $2.5,4$, and $5.5 \mathrm{~h}$ were carried out. The damage mechanism was analyzed using scanning electron microscopy, mercury intrusion porosimetry, thermal analysis, and X-ray diffraction phase analysis. The results demonstrate that cellulose fiber can reduce the performance loss of concrete at high temperatures; the effect of holding time on the performance is more noticeable below $600^{\circ} \mathrm{C}$. After exposure to high temperatures, the performance of ordinary concrete deteriorates faster and spalls at $700-800^{\circ} \mathrm{C}$; in contrast, cellulose fiber melts at a higher temperature, leaving a series of channels in the matrix that facilitate the release of the steam pressure inside the CFRC. Hollow cellulose fibers can thereby slow the damage caused by internal stress and improve the spalling resistance of concrete under high temperatures.
\end{abstract}

\section{Introduction}

In the past decade, cellulose fiber-reinforced concrete (CFRC) has been used in construction of high speed railways, subway tunnels, and urban underground pipelines in China because of its high crack resistance and durability. Guo [1-3] designed the CFRC with a compressive grade of C30, which has high performance characteristics, including impermeability, crack resistance, long bending fatigue life, and predicted long service life for underground concrete infrastructures. The replacement of rebar-reinforced concrete tunnel linings by this CFRC in 400 tunnels on the GuiyangGuangzhou and Hefei-Fuzhou express railways has saved more than USD 200 million. Some revised models [1-3] have predicted the service life of this material to be more than 100 times that of the designed life.
High temperatures and attack by fire are, however, dangerous for the tunnel linings of express railways and subways. Frequent fire accidents around the world have caused tremendous casualties and millions of dollars in economic losses. In February 1979, a fire on the San Francisco (USA) subway killed one person, injured 56 people, destroyed five metro trains, and caused direct economic losses of USD 8 million. In 1995, a fire on the Baku metro, Azerbaijan, killed 558 and injured 269 persons. In January 1999, 53 hours of continuous fire in the Mont Blanc highway tunnel in Italy killed 39 people and destroyed more than 30 cars. In January 2015, the Channel Tunnel was shut down for an extended period because of a freight train that had caught fire. Consequently, the high-temperature resistance of CFRC is paid increasing attention by designers. When exposed to fire, rapidly rising temperatures cause concrete covers to 
TABLE 1: Physical and mechanical properties of cellulose fiber.

\begin{tabular}{|c|c|c|c|c|c|}
\hline $\begin{array}{l}\text { Ultimate tensile } \\
\text { strength }(\mathrm{MPa})\end{array}$ & $\begin{array}{c}\text { Elastic modulus } \\
(\mathrm{GPa})\end{array}$ & $\begin{array}{c}\text { Ultimate } \\
\text { elongation }(\%)\end{array}$ & $\begin{array}{c}\text { Equivalent } \\
\text { diameter }(\mu \mathrm{m})\end{array}$ & $\begin{array}{c}\text { Mean length } \\
(\mathrm{mm})\end{array}$ & Density $\left(\mathrm{g} / \mathrm{cm}^{3}\right)$ \\
\hline $600-900$ & $9.0-10.0$ & 3.5 & $15-20$ & $2.1-5.3$ & 1.1 \\
\hline
\end{tabular}

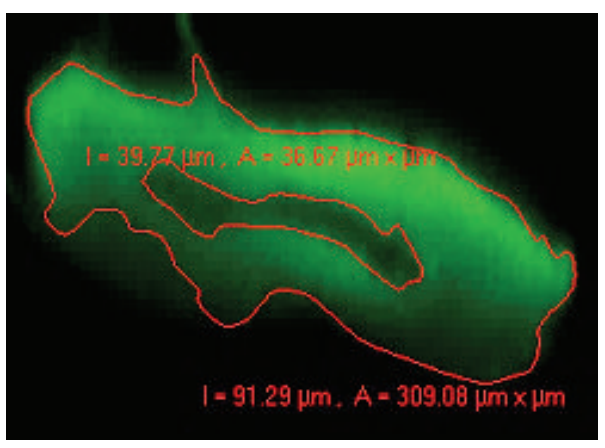

(a)

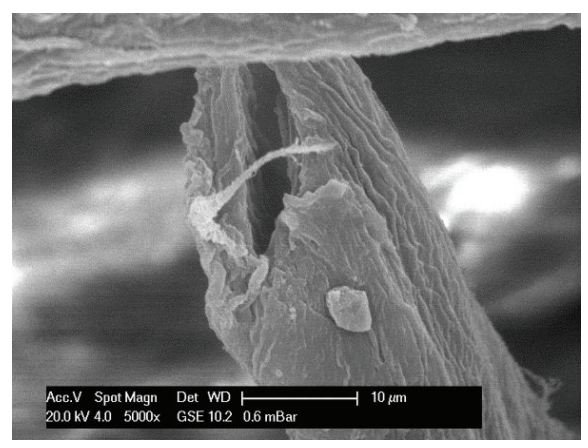

(b)

FIGURE 1: Cross-sectional morphology of cellulose fiber captured by (a) LSCM and (b) FESEM.

suddenly burst without warning and the associated structures lose their loading capacity within a short time. Moreover, fire extinguishing and rescue are very difficult in relatively closed environments like tunnels. Ensuring the structural integrity of tunnel structures to prolong the available rescue time has therefore focused research on the high-temperature performance of these kinds of structures $[4,5]$. In past decade, many researchers have studied different kinds of fibers for improving the high-temperature resistance of concrete, including steel, polypropylene, and polyvinyl alcohol $[6,7]$. The results show that synthetic fibers are better than steel fibers for this purpose. The high-temperature resistance properties of CFRC have, however, rarely been reported to date.

To clarify the spalling resistance performance and damage mechanisms of CFRC exposed to high temperatures, we investigated the mass loss, relative dynamic elastic modulus, compressive strength, and splitting tensile strength of CFRC under different high temperatures $(300,600,800$, and $1050^{\circ} \mathrm{C}$ ) for different isothermal periods $(2.5,4$, and $5.5 \mathrm{~h}$ ). The damage mechanisms were analyzed using microanalytical techniques, including field-emission scanning electron microscopy (FESEM), thermogravimetric analysis, differential scanning calorimetry (DSC), mercury intrusion porosimetry (MIP), and X-ray diffraction (XRD). The melting point and internal-curing properties of cellulous fiber were also tested to understand the effects of cellulous fiber on the high-temperature performance of CFRC.

\section{Materials and Methods}

2.1. Raw Materials and Design of Concrete Mix. P.II 42.5 Portland cement (C) and Class F fly ash (FA), with specific surface areas of $370 \mathrm{~m}^{2} / \mathrm{kg}$ and $455 \mathrm{~m}^{2} / \mathrm{kg}$, respectively, were used as the cementitious materials for the CFRC. The apparent densities are $3.1 \mathrm{~g} / \mathrm{cm}^{3}$ and $2.35 \mathrm{~g} / \mathrm{cm}^{3}$ for PC and
FA, respectively. The ignition loss of FA is $2.5 \%$. Crushed limestone particles and river sand were selected as the coarse and fine aggregates, respectively. The particle size of the coarse aggregate was $5-20 \mathrm{~mm}$ and that of the fine aggregate was $0.15-2.36 \mathrm{~mm}$. Their respective apparent densities were $2720 \mathrm{~kg} / \mathrm{m}^{3}$ and $2650 \mathrm{~kg} / \mathrm{m}^{3}$. The fineness modulus of the fine aggregate was 2.7. A high-performance polycarboxylate superplasticizer (PS) was added to adjust the flowability of fresh CFRC. Its solid content was $20 \%$ and its water reduction exceeded $25 \%$. Tap water was used as the blending medium. The slump loss of fresh CFRC within one hour was less than $80 \mathrm{~mm}$.

A modified cellulous fiber (CF) made from a wing celtis bark from the United States was used as the reinforcement and crack-resistant phase for the CFRC microstructure. The physical and mechanical properties of the CF are presented in Table 1. It is clear that the properties of CF used as an engineering fiber in concrete are quite different to those in papermaking effluents.

CF has a very special microstructure, comprising a continuous hollow inside. This acts as a micro water reservoir for cement hydration during long aging times and is of benefit in ensuring a homogeneous and dense microstructure of CFRC as an internal-curing phase. We employed a laser scanning confocal microscope (LSCM) and FESEM for characterizing this microstructure. Figure 1(a) shows a cross section of CF impregnated by a fluorescent agent and captured by LSCM. Figure 1(b) presents another profile of a CF cut by an alloy blade slicing machine. These morphologies provide evidence for the hollow microstructure of CF. The internal and external areas of the tested CF are about 37 and $309 \mu \mathrm{m}^{2}$, respectively. The wall thickness is about $3-5 \mu \mathrm{m}$.

Because of this special microreservoir effect, the water absorption behavior of CF is notable during the concrete mixing process and is higher than those of solid fibers such as polyvinyl alcohol and polypropylene. We tested the five 
TABLE 2: Water absorption ratio of cellulose fibers.

\begin{tabular}{lcccc}
\hline Sample number & Dried mass $(\mathrm{g})$ & Saturated mass $(\mathrm{g})$ & Differential value of mass $(\mathrm{g})$ & Water absorption ratio $(\%)$ \\
\hline CF-1 & 1.01 & 3.44 & 2.42 & 240 \\
CF-2 & 0.98 & 3.31 & 2.33 & 238 \\
CF-3 & 1.00 & 3.40 & 2.40 & 240 \\
CF-4 & 1.02 & 3.45 & 2.43 & 238 \\
CF-5 & 1.01 & 3.43 & 2.43 & 241 \\
Mean value & 1.00 & 3.41 & 2.40 & 239 \\
\hline
\end{tabular}

TABLE 3: Mix proportions of concrete $\left(\mathrm{kg} / \mathrm{m}^{3}\right)$.

\begin{tabular}{lccccccc}
\hline Concrete series & C & FA & Fine aggregate & Coarse aggregate & Blend water & PS & CF \\
\hline PC & 266 & 114 & 760 & 1050 & 155 & 3.04 \\
CFRC & 266 & 114 & 760 & 1050 & 155 & 3.04 & 0.9 \\
\hline
\end{tabular}

fiber samples displayed in Table 2 and determined their mean value of water absorption as $239 \%$. This test result also shows that CF has good hydrophilic and water-retentive properties, which are of benefit for fiber dispersion and flowability of fresh CFRC.

Because of cement hydration and strength progression of CFRC after being cured for more than $28 \mathrm{~d}$, the previously retained water inside the $\mathrm{CF}$ will be extracted to the exterior to improve the density of the CFRC microstructure. As a result, the $\mathrm{CF}$ dries and shrinks while the hollow spaces remaining inside the $\mathrm{CF}$ and the coarse interface between CFs and hardened cement pastes assist in dissipating the vapor pressure and improving the resistance of CFRC at high temperatures.

All of the above raw materials were optimized for concrete design. The design strength grade of the concrete is C30. The optimized mix proportions of CFRC and the reference concrete (PC) are shown in Table 3. According to our previous research results [2], the optimized mass fraction of CF required to economically achieve a CFRC with high durability is $0.9 \mathrm{~kg} / \mathrm{m}^{3}$; this optimized fraction of CF is also used in the present research. The slump and air contents of the fresh CFRC were $180 \pm 20 \mathrm{~mm}$ and $2-3 \%$, respectively.

The size of concrete specimens was $100 \mathrm{~mm} \times 100 \mathrm{~mm} \times$ $100 \mathrm{~mm}$. After casting into a steel mold for $24 \mathrm{~h}$, concrete specimens were demolded and placed in a standard curing room for $28 \mathrm{~d}$ before use.

2.2. Test Methods. The morphology of the CF cross-sectional profile was determined using LSCM and SEM. The water absorption behavior of CF was determined using the tea bag method given in the Japanese Standard "Test Method for Water Absorption of Textiles (JIS L1907-2010)." This test involves placing $1 \mathrm{~g}$ of CF sample into a tea bag made of nonwoven fabric and then immersing this bag into distilled water for $30 \mathrm{~min}$. After removing it from the water and hanging it in a laboratory until it no longer drips, the $\mathrm{CF}$ sample is placed on a filter paper to absorb any surface water. The saturated water absorption ratio of CF is characterized according to the method given in the standard.
The high-temperature performance of the concrete was tested using a resistance furnace (SXO-5-12A, Nanjing, China) with a maximum temperature of $1200^{\circ} \mathrm{C}$ and average heating rate of $15^{\circ} \mathrm{C} / \mathrm{min}$. The initial temperature of the concrete cubes was $20^{\circ} \mathrm{C}$. After heating the concrete to a set temperature (i.e., $300,600,800$, or $1050^{\circ} \mathrm{C}$ ), the furnace was held at constant temperature for different times (i.e., 2.5, 4, and $5.5 \mathrm{~h}$ ). The furnace was then switched off and the concrete cubes were slowly cooled to room temperature in the furnace.

The microstructural morphologies of the fiber and concrete were measured using an FESEM (Quanta 3D FEG, FEI Company, Eindhoven, Netherlands) with a maximum resolution of $50 \mathrm{~nm}$. The porosity and pore size distribution of the concrete samples were measured by a MIP (AutoPore IV 9500, Micromeritics Instrument Corp., Norcross, USA). The decomposition of the chemical phases and CF fibers was evaluated using a thermogravimetric-DSC synchronous thermal analyzer (STA 449 F3 Jupiter, NETZSCH-Gerätebau $\mathrm{GmbH}$, Selb, Germany). The chemical components of the concrete were characterized by X-ray diffraction (SmartLab, Rigaku, Osaka, Japan).

\section{Results and Discussion}

3.1. Physical Properties. The physicochemical performance of concrete gradually degenerates with increasing temperature. At $200^{\circ} \mathrm{C}$, a small amount of visible water vapor escaped from the furnace door, which was a result of evaporation of free water from the concrete. With constant heating, calcium hydroxide-as the main cement hydrate in the concrete-gradually decomposes. At $600^{\circ} \mathrm{C}$, the white steam disappeared and the concrete was almost dehydrated. The water evaporation and decomposition of the components cause mass loss of concrete. Comparing the mass loss with the initial mass of the tested concrete, a mass loss ratio can be defined for evaluating the physicochemical degradation of concrete specimens exposed to high temperature.

In addition to the mass loss at high temperatures, the water vapor pressure and thermal expansion inside the concrete will damage its microstructure and eventually cause 
TABLE 4: Influence of high temperatures on physical properties of concrete.

\begin{tabular}{|c|c|c|c|c|}
\hline Concrete series & Temperature $\left({ }^{\circ} \mathrm{C}\right)$ & Holding time $(\mathrm{h})$ & Mass loss ratio (\%) & Relative elastic modulus (\%) \\
\hline \multirow{7}{*}{ PC } & 20 & - & - & - \\
\hline & & 2.5 & 3.6 & 77 \\
\hline & 300 & 4 & 6.2 & 67 \\
\hline & & 5.5 & 7.6 & 60 \\
\hline & & 2.5 & 8.5 & 22 \\
\hline & 600 & 4 & 11.7 & 17 \\
\hline & & 5.5 & 12.7 & 14 \\
\hline \multirow{13}{*}{ CFRC } & 20 & - & - & - \\
\hline & & 2.5 & 3.4 & 82 \\
\hline & 300 & 4 & 4.8 & 74 \\
\hline & & 5.5 & 5.6 & 69 \\
\hline & & 2.5 & 6.2 & 27 \\
\hline & 600 & 4 & 6.5 & 25 \\
\hline & & 5.5 & 7.5 & 24 \\
\hline & & 2.5 & 10.5 & 12 \\
\hline & 800 & 4 & 12.3 & 11 \\
\hline & & 5.5 & 14.3 & 10 \\
\hline & & 2.5 & 20.5 & 5 \\
\hline & 1050 & 4 & 22.1 & 5 \\
\hline & & 5.5 & 28.4 & 4 \\
\hline
\end{tabular}

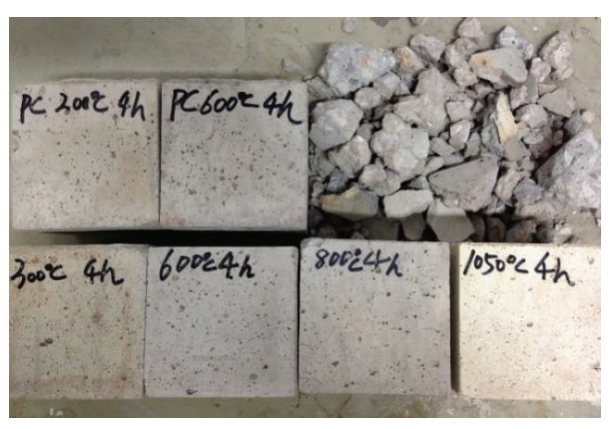

(a)

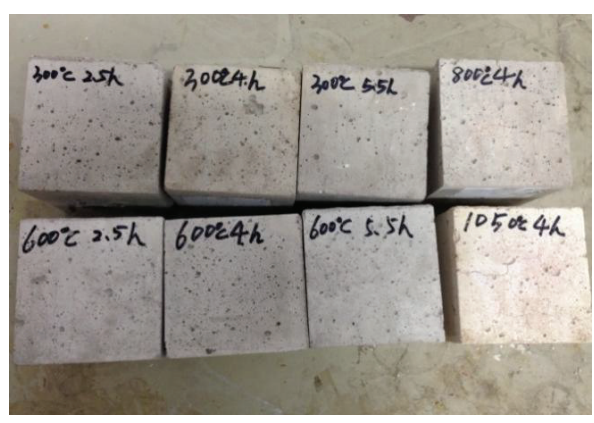

(b)

FIGURE 2: Appearances of (a) PC and (b) CFRC concrete after heating to different temperatures for different times.

spalling. The relative elastic modulus, detected by a nondestructive ultrasonic detector, is an effective parameter for characterizing the degree of damage of concrete exposed to different temperatures.

The appearances of the concrete after exposure to different temperatures for different periods of time are compared in Figure 2. The respective mass loss ratios and relative elastic moduli are presented in Table 4.

As shown in Figure 2, there are no PC data for temperatures above $600^{\circ} \mathrm{C}$ because the specimens suddenly explode into fragments when heating at this temperature; however, the CFRCs retain integrity at temperatures as high as $1050^{\circ} \mathrm{C}$ for the various holding times. The appearance of the heated specimens also changes with increasing temperatures: PC changed from a dark grey color to brick red, while the CFRC changed from dark grey to a milky color.
After constant heating at $300^{\circ} \mathrm{C}$ for different holding times, both the PC and CFRC specimens changed color without the appearance of macroscopic cracks. On heating at $600^{\circ} \mathrm{C}$ for $2.5 \mathrm{~h}$ and $4 \mathrm{~h}$, however, a greater number of pores and microcracks appeared on the PC surfaces. PC samples were flaked, broken, and spalled after heating at $600^{\circ} \mathrm{C}$ for $5.5 \mathrm{~h}$. In contrast, the CFRC specimens remained intact without serious damage, except for the presence of some small voids, when heated to this temperature for the three holding times considered. On heating at $800^{\circ} \mathrm{C}$ for different holding times, the PC specimens burst and totally failed because of internal thermal expansion and vapor pressures, while the CFRCs maintained relative integrity except for the formation of some large voids and crack networks on the surface. On heating at $1050^{\circ} \mathrm{C}$, the CFRCs changed to a milky color and showed macrocrack network damage and slightly warped corners. 
TABLE 5: Influence of high temperature on mechanical properties of concrete.

\begin{tabular}{|c|c|c|c|c|}
\hline Concrete series & Temperature $\left({ }^{\circ} \mathrm{C}\right)$ & Holding time (h) & $\begin{array}{c}\text { Loss ratio of } \\
\text { compressive strength } \\
(\%) \\
\end{array}$ & $\begin{array}{l}\text { Loss ratio of splitting } \\
\text { tensile strength }(\%)\end{array}$ \\
\hline \multirow{7}{*}{ PC } & 20 & - & - & - \\
\hline & \multirow{3}{*}{300} & 2.5 & 12 & 2 \\
\hline & & 4 & 20 & 20 \\
\hline & & 5.5 & 30 & 34 \\
\hline & \multirow{3}{*}{600} & 2.5 & 65 & 48 \\
\hline & & 4 & 68 & 67 \\
\hline & & 5.5 & 70 & 83 \\
\hline \multirow{13}{*}{ CFRC } & 20 & - & - & - \\
\hline & \multirow{3}{*}{300} & 2.5 & 3 & 2 \\
\hline & & 4 & 6 & 3 \\
\hline & & 5.5 & 17 & 29 \\
\hline & \multirow{3}{*}{600} & 2.5 & 47 & 52 \\
\hline & & 4 & 54 & 65 \\
\hline & & 5.5 & 60 & 72 \\
\hline & \multirow{3}{*}{800} & 2.5 & 78 & 77 \\
\hline & & 4 & 82 & 81 \\
\hline & & 5.5 & 80 & 80 \\
\hline & \multirow{3}{*}{1050} & 2.5 & 87 & 91 \\
\hline & & 4 & 90 & 93 \\
\hline & & 5.5 & 92 & 95 \\
\hline
\end{tabular}

Table 4 shows, furthermore, that the relative elastic modulus exceeds $60 \%$ and the mass loss ratio is less than $6 \%$ for $\mathrm{PC}$ heated at $300^{\circ} \mathrm{C}$ for $2.5 \mathrm{~h}$ but that these properties are also observed for CFRC heated at this temperature for $5.5 \mathrm{~h}$. The microstructures of the tested concrete are only slightly damaged during this process, which meets the requirements for engineering applications. During heating at $600^{\circ} \mathrm{C}$, the mass loss ratio is less than $10 \%$ and the relative elastic modulus exceeds $20 \%$ for PC heated for $2.5 \mathrm{~h}$ and for CFRC heated for $5.5 \mathrm{~h}$, and the cracks were obvious on PC surface. After heating above $800^{\circ} \mathrm{C}$, the $\mathrm{PC}$ samples burst to failure but the CFRC samples maintain integrity with network cracks; however, above $600^{\circ} \mathrm{C}$, the heated CFRCs can no longer bear any load.

3.2. Mechanical Properties. The residual loading capacity is a critical parameter for the high-temperature performance of concrete. The residual compressive strength and split tensile strength are the two basic parameters used as a theoretical basis for structure security evaluation. We measured these two strengths of concrete after it was heated to different temperatures and for different holding times, as shown in Table 5.

When heating to $300^{\circ} \mathrm{C}$ and holding for different times, the strength loss ratios (i.e., a ratio between final strength and original strength of tested specimens) of both PC and CFRC samples were less than 30\%; however, those results obviously changed with holding time. The CFRC ratios were less than
$10 \%$ for holding times of 2.5 and $4 \mathrm{~h}$, which is $1 / 4-1 / 3$ the strength of the PC samples. When the holding time was $5.5 \mathrm{~h}$, the compressive strength loss ratio of CFRC was $50 \%$ less than that of PC. The compressive strength loss ratio was less than $60 \%$ for PC heated at $300^{\circ} \mathrm{C}$ for $5.5 \mathrm{~h}$ compared with the same performance of CFRC heated at $600^{\circ} \mathrm{C}$ for $5.5 \mathrm{~h}$. Similarly, the splitting tensile strength loss ratio was less than $30 \%$ for PC heated at $300^{\circ} \mathrm{C}$ for $4 \mathrm{~h}$ while the same value was achieved for $\mathrm{CFRC}$ heated at $300^{\circ} \mathrm{C}$ for $5.5 \mathrm{~h}$.

When heated to $600^{\circ} \mathrm{C}$, the strength losses of the PC samples were $60 \%$ and $130 \%$ times higher than those of CFRC. A temperature of $300^{\circ} \mathrm{C}$ is close to the softening point of cellulous fiber, as subsequently verified.

When the temperature was $800^{\circ} \mathrm{C}, \mathrm{PC}$ collapsed because of fragmentation, while CFRC was severely damaged and the strength losses were around $80 \%$. CFRCs almost failed after heating at $1050^{\circ} \mathrm{C}$. We can conclude that this special cellulous fiber is effective for improving spalling resistance and residual loading capacity of concrete exposed to high temperatures for different holding times.

\section{Multiscale Physicochemical and Thermal Mechanisms}

To determine the multiscale mechanisms of CF in improving the high-temperature performance of concrete, advanced analytical equipment was employed for analyzing its physicochemical and thermal actions. Because the above-mentioned 


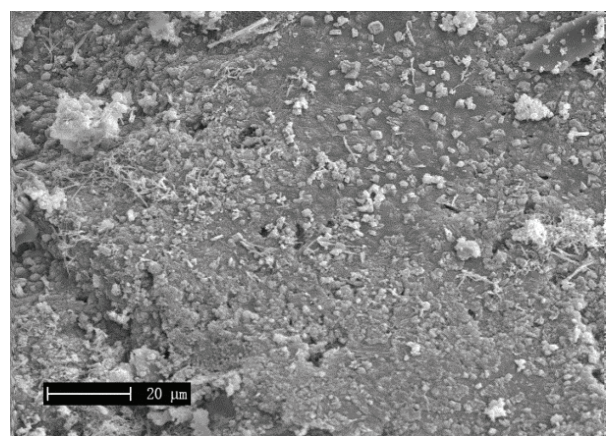

(a)

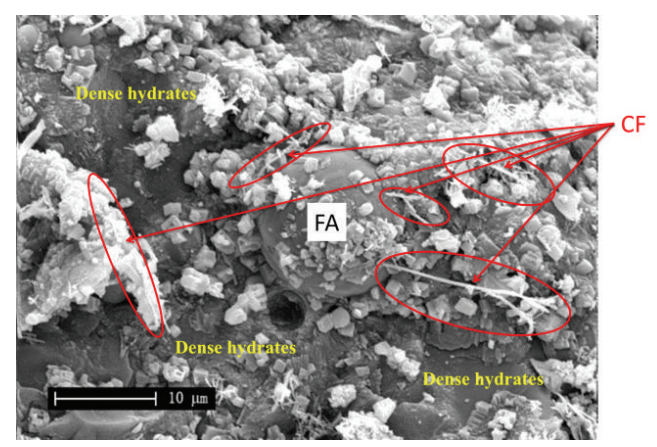

(b)

FIGURE 3: SEM images of microstructure of CFRC at $20^{\circ} \mathrm{C}$ at (a) $2000 \mathrm{x}$ and (b) $5000 \mathrm{x}$ magnification.

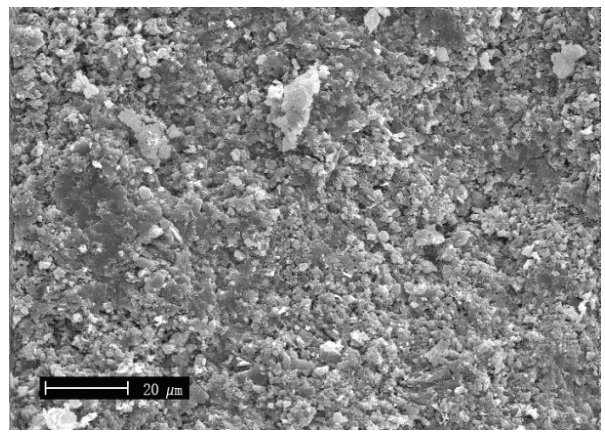

(a)

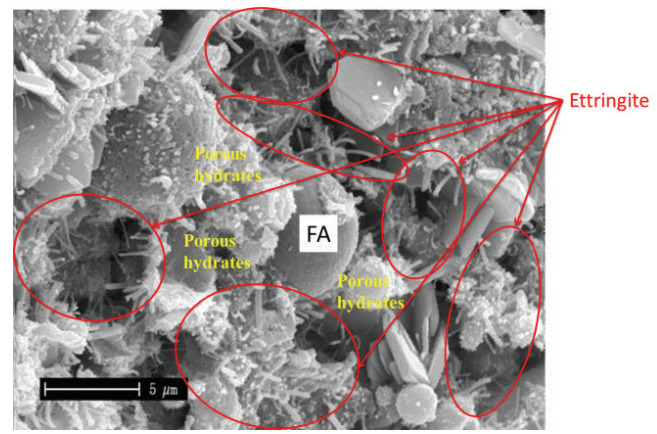

(b)

Figure 4: SEM images of microstructure of $\mathrm{PC}$ at $20^{\circ} \mathrm{C}$ at (a) 2000x and (b) $10000 x$ magnification.

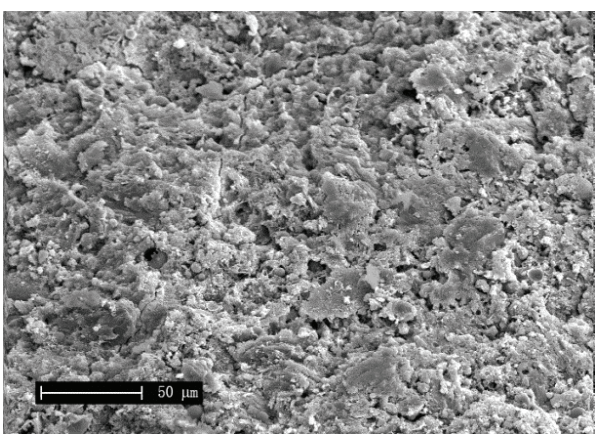

(a)

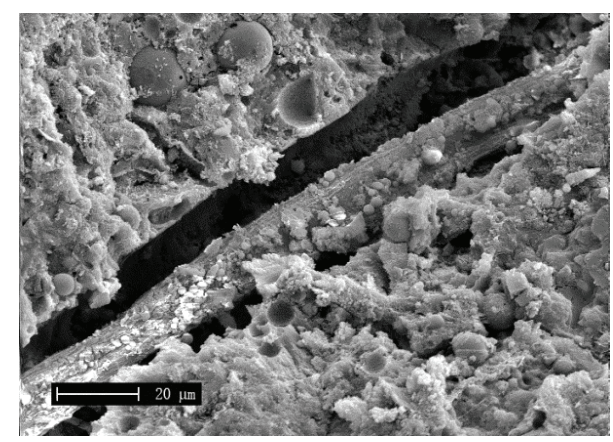

(b)

FIGURE 5: SEM images of microstructure of CFRC exposed at $300^{\circ} \mathrm{C}$ for $2.5 \mathrm{~h}$ at (a) $1000 \mathrm{x}$ and (b) $2000 \mathrm{x}$ magnification.

physical and mechanical properties of the tested concrete were obviously weakened at $300^{\circ} \mathrm{C}$ and $600^{\circ} \mathrm{C}$ for different holding times, the evolution of the concrete microstructures with temperature was monitored.

4.1. Microstructural Morphology. The effects of temperatures and holding time on the degradation of the concrete microstructures were investigated by FESEM and are presented in Figures 3-13.

Comparing Figures 3 and 4, it is clear that the CFRC microstructure at $20^{\circ} \mathrm{C}$ is denser than that of $\mathrm{PC}$ and its main hydrates are smaller and more uniform. The coarse calcium hydroxide and bulky needlelike ettringites observed in PC (Figure 4) cannot be easily found in CFRC (Figure 3). Some long needlelike CFs evenly disperse in CFRC. The interfacial zones between the cement paste and unreacted fly ash particles are dense in CFRC but porous in PC.

After heating at $300^{\circ} \mathrm{C}$ for $2.5 \mathrm{~h}$, some network cracks and porous voids appear in the PC microstructure, which support the observed degraded mechanical and physical properties shown in Tables 4 and 5. In contrast, the CFRC microstructure indicated the presence of some nonconnected 


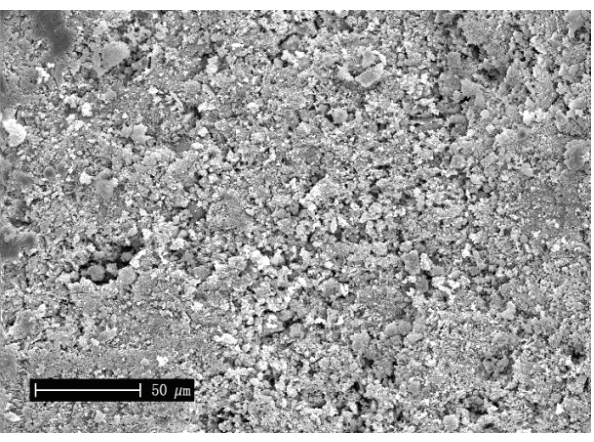

(a)

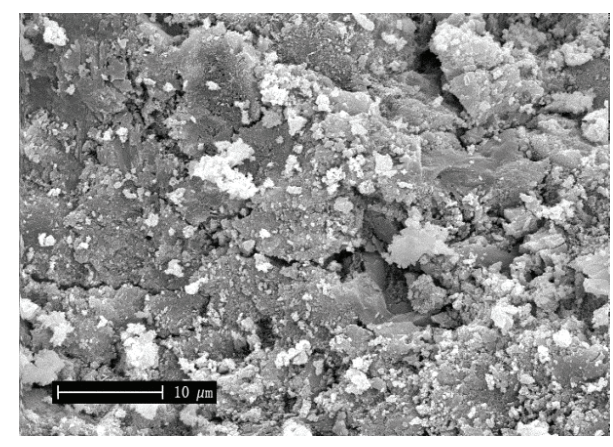

(b)

FIGURE 6: SEM images of microstructure of PC exposed at $300^{\circ} \mathrm{C}$ for $2.5 \mathrm{~h}$ at (a) $1000 \mathrm{x}$ and (b) 5000x magnification.

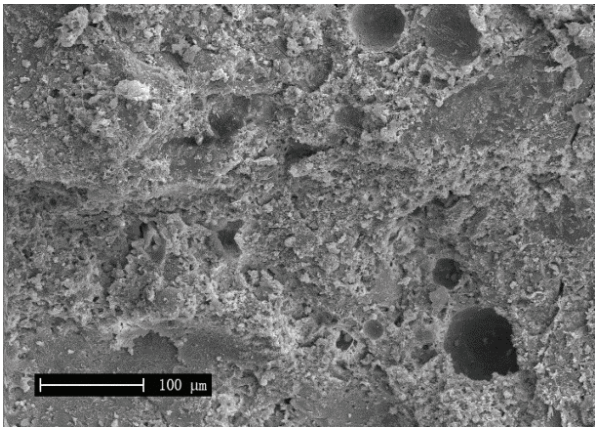

(a)

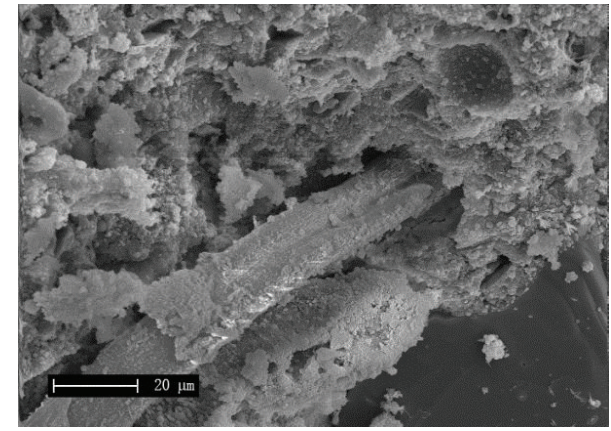

(b)

FIgURE 7: SEM images of microstructure of CFRC exposed at $300^{\circ} \mathrm{C}$ for $4 \mathrm{~h}$ at (a) $500 \mathrm{x}$ and (b) $2000 \mathrm{x}$ magnification.

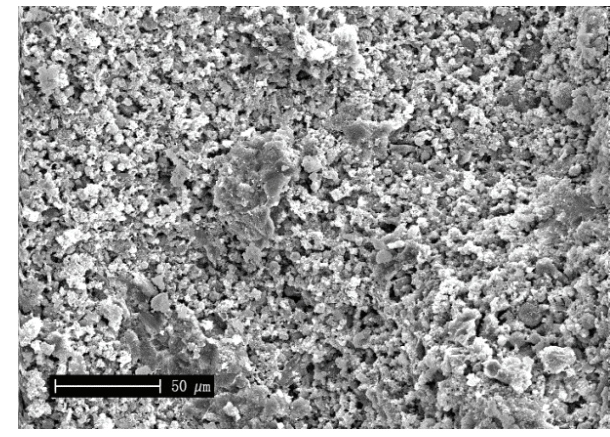

(a)

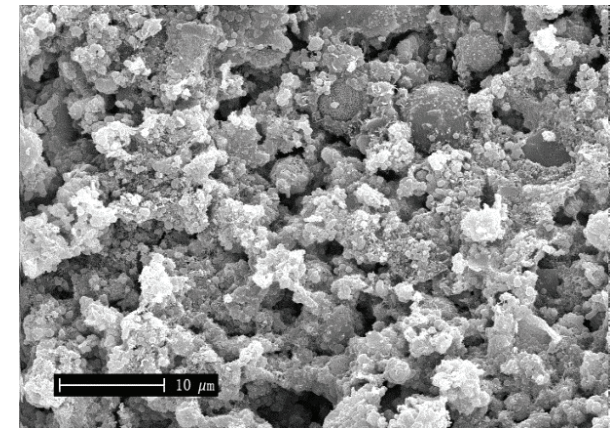

(b)

FIGURE 8: SEM images of microstructure of PC exposed at $300^{\circ} \mathrm{C}$ for $4 \mathrm{~h}$ at (a) $1000 \mathrm{x}$ and (b) 5000x magnification.

microcracks while the CFs debonded from the concrete matrix because of dry shrinkage. As discussed for Tables 4 and 5, CFRC still has sufficient loading capacity and integral macrostructure in this case.

Comparing Figures 5 and 7, we find a greater number of micropores in CFRC after being heated at $300^{\circ} \mathrm{C}$ for $4 \mathrm{~h}$, because some CFs were partly fused. Some initially connected hydrates are slightly decomposed inside the CFRC. According to Tables 4 and 5, the mechanical and physical properties of CFRCs are not obviously weakened in this case; however, as shown in Figure 8, some hydrates transform to separated particles and more connected microcracks appear inside the $\mathrm{PC}$, which provide reasons for the obvious degradation of PC properties after being heated at $300^{\circ} \mathrm{C}$ for $4 \mathrm{~h}$.

On heating the $\mathrm{CFRC}$ at $300^{\circ} \mathrm{C}$ for $5.5 \mathrm{~h}$, more $\mathrm{CFs}$ obviously fuse, leaving more pores inside the concrete. Fused CFs also leave large distances between them and the concrete matrix and greater numbers of microcracks simultaneously appear, as shown in Figure 9. Figure 10 shows that the microstructure of PCs became more porous and the initially 


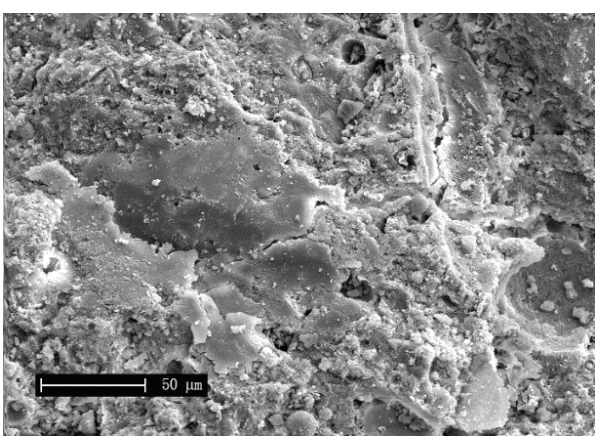

(a)

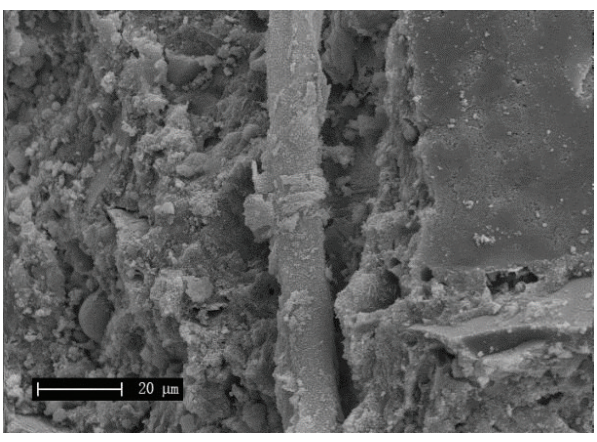

(b)

FIGURE 9: SEM images of microstructure of CFRC exposed at $300^{\circ} \mathrm{C}$ for $5.5 \mathrm{~h}$ at (a) $1000 \mathrm{x}$ and (b) 2000x magnification.

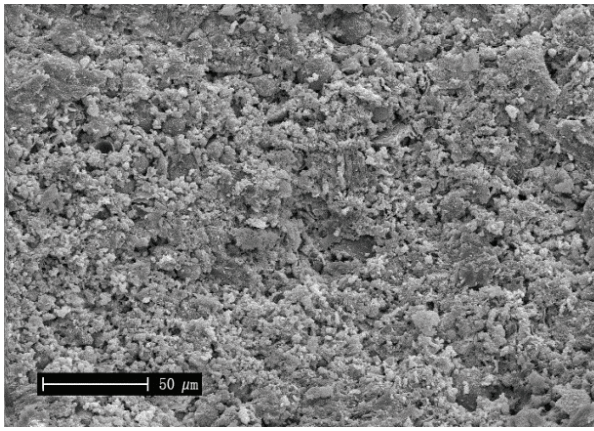

(a)

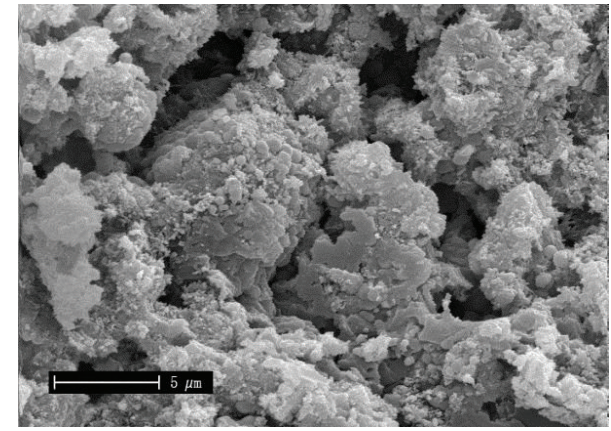

(b)

Figure 10: SEM images of microstructure of PC exposed at $300^{\circ} \mathrm{C}$ for $5.5 \mathrm{~h}$ at (a) $1000 \mathrm{x}$ and (b) $10000 \mathrm{x}$ magnification.

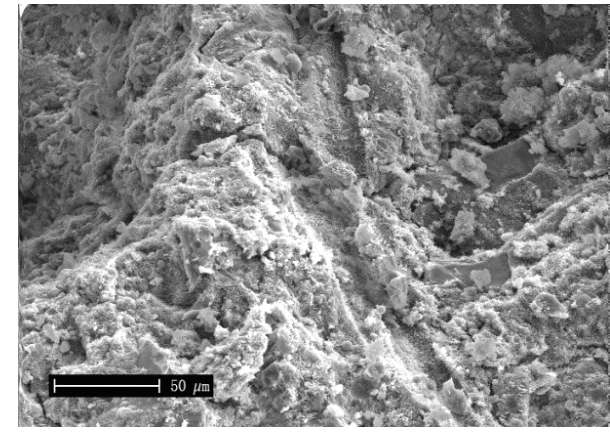

(a)

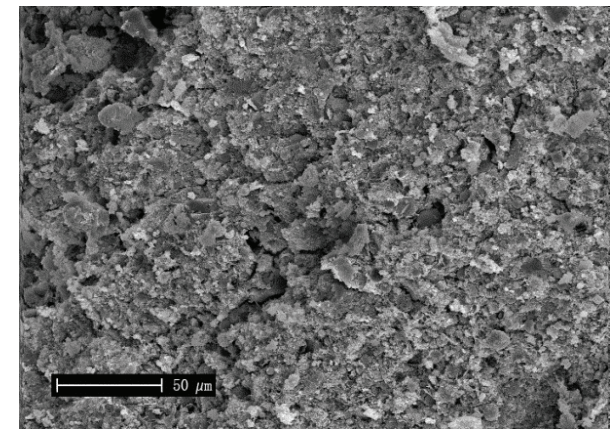

(b)

FIgURE 11: SEM images of microstructure of (a) CFRC and (b) PC concrete exposed to $600^{\circ} \mathrm{C}$ for $4 \mathrm{~h}$ (1000x magnification).

large hydrates decomposed to tiny particles. This can explain why the mechanical properties of PCs suddenly degraded in this case.

As shown in Figure 11, on heating CFRC at $600^{\circ} \mathrm{C}$, most CFs fused, leaving more pores in the microstructure. Furthermore, more microcracks progressed to connected nets and some cement hydrates also decomposed. The CFRC mechanical strength loss ratio exceeded 50\%, which means that its load capacity in this condition cannot accommodate any further loading.
Figure 12 shows the microstructure morphology of CFRC heated at $800^{\circ} \mathrm{C}$. Similar to the condition of PC shown in Figure 8, some cement hydrates (such as calcium silicate hydrate $(\mathrm{C}-\mathrm{S}-\mathrm{H})$ gels) dehydrate and $\mathrm{CH}$ decomposes. The mechanical properties of CFRCs dramatically deteriorate under these conditions. Finally, on heating at $1050^{\circ} \mathrm{C}$, rare bulk hydrates exist in the CFRC but are mainly transformed to glass. Although the mechanical properties are almost lost at this temperature, the heated CFRC retains an integrated appearance. 


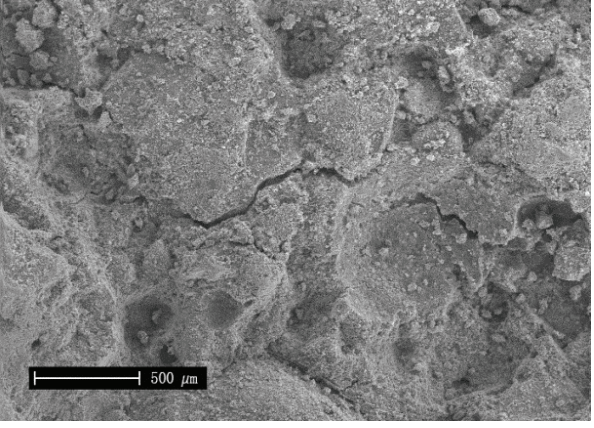

(a)

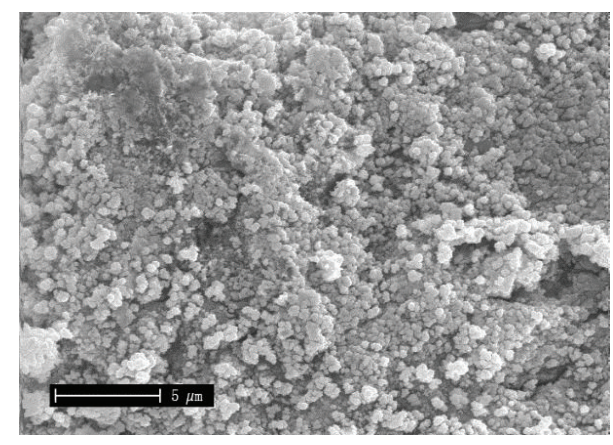

(b)

FIGURE 12: SEM images of microstructure of CFRC exposed at $800^{\circ} \mathrm{C}$ for $4 \mathrm{~h}$ at (a) $100 \mathrm{x}$ and (b) $10000 \mathrm{x}$ magnification.

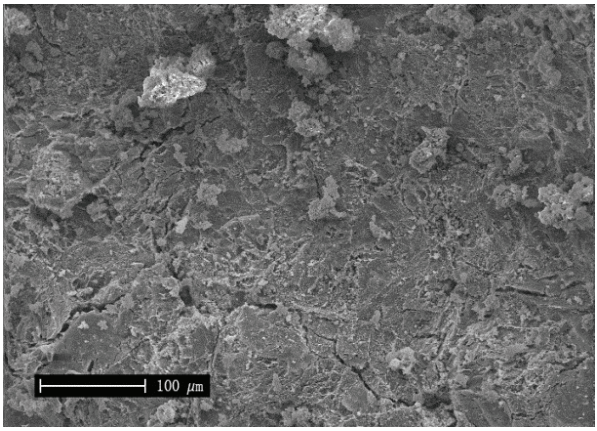

(a)

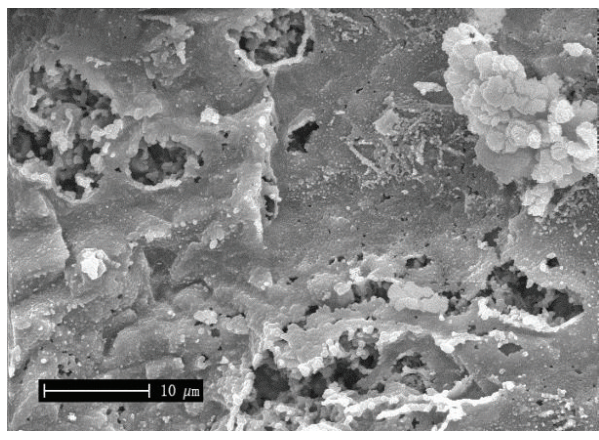

(c)

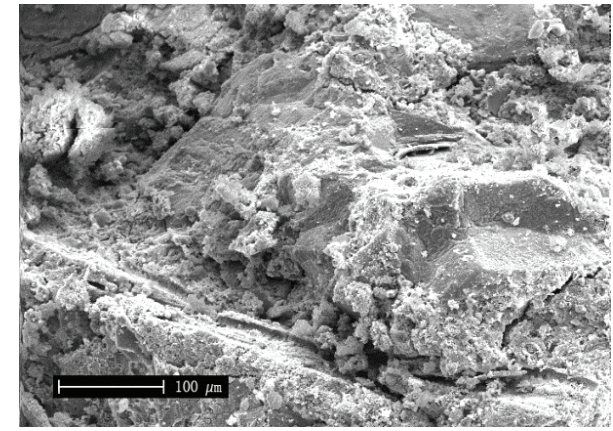

(b)

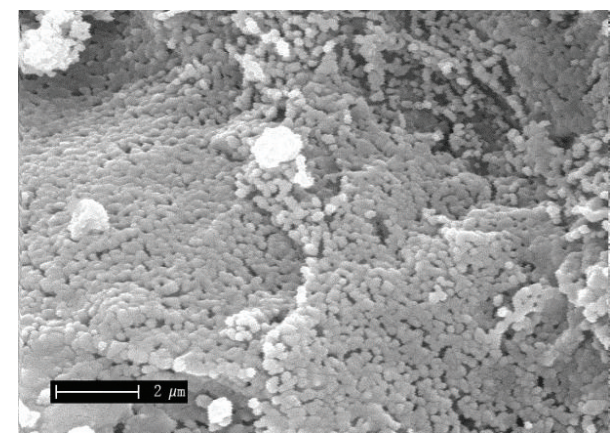

(d)

FIGURE 13: SEM images of microstructure of CFRC exposed at $1050^{\circ} \mathrm{C}$ for $4 \mathrm{~h}$ at (a) 500x, (b) 500x, (c) 5000x, and (d) $20000 \mathrm{x}$ magnification.

4.2. Pore Structure. As mentioned above, the pore structures in the tested concrete change with increasing temperature and holding time, so an evaluation of differences in porosity and pore size distribution between PC and CFRC was undertaken. MIP is an effective method for this purpose. The MIP measuring range used in this research is from $2.5 \mathrm{~nm}$ to $100 \mu \mathrm{m}$.

Pores in concrete can be categorized into four classes according to their adverse effects on durability of concrete [8]: that is, harmless pores of less than $20 \mathrm{~nm}$; slightly dangerous pores with sizes from 20 to $50 \mathrm{~nm}$; dangerous pores with sizes of 50 to $200 \mathrm{~nm}$; and highly dangerous pores with sizes larger than $200 \mathrm{~nm}$. The performance of concrete can be obviously enhanced by increasing the number of pores of less than $50 \mathrm{~nm}$ diameter and decreasing the number of pores larger than $100 \mathrm{~nm}$. We can therefore compare our test results with these parameters to identify the degree of damage and explain the damage micromechanism of the tested concrete after being heated at different temperatures and for different holding times.

The porosity curves for PC and CFRC exposed to different temperatures are shown in Figures 14-17. The porosity of concrete increases with temperature, which is consistent with the observations of the SEM figures. The four pore size categories can be identified from the respective logarithmic differential intrusion curves, where the most probable pore size is given by the maximum value of these curves. The porosities of heated CFRCs increase from $20^{\circ} \mathrm{C}$ to $800^{\circ} \mathrm{C}$ : 


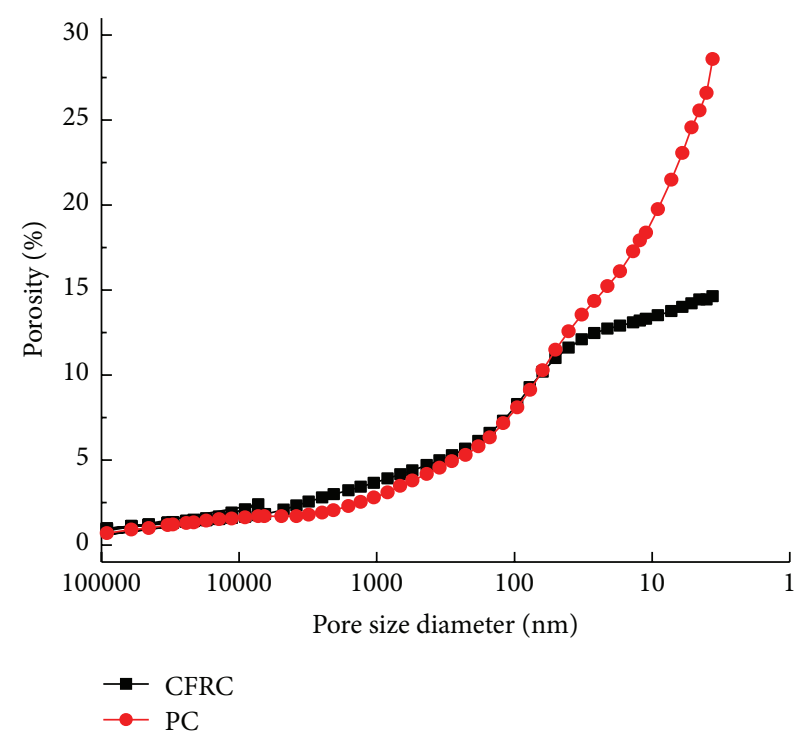

(a)

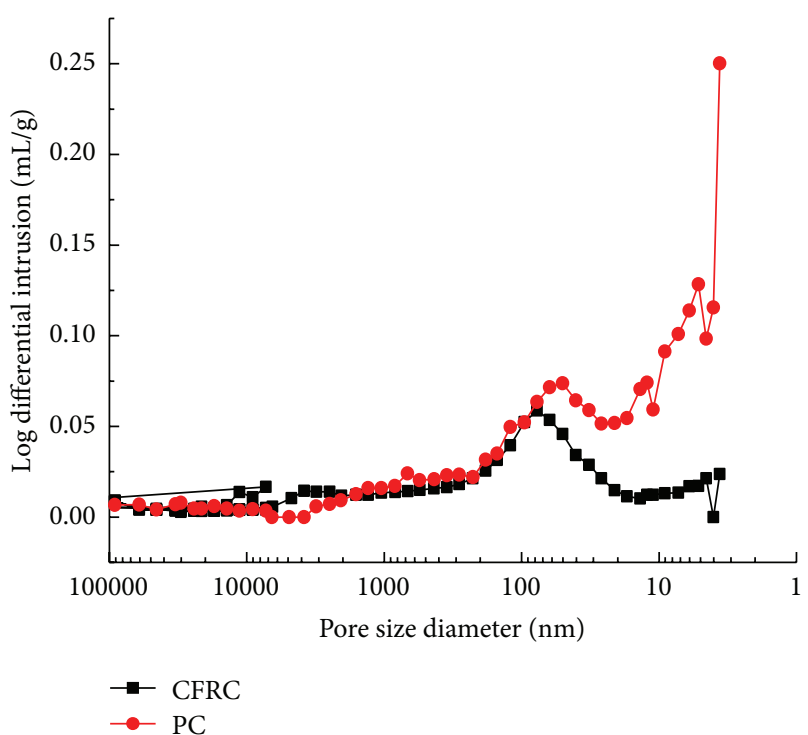

(b)

FIgURE 14: Pore size distributions of CFRC and PC at room temperature $\left(20^{\circ} \mathrm{C}\right)$.

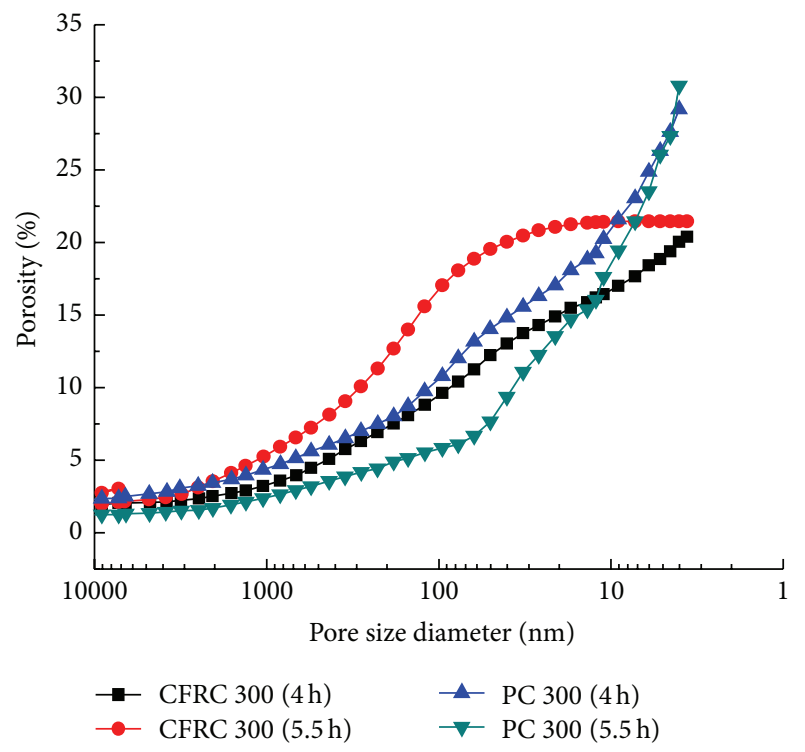

(a)

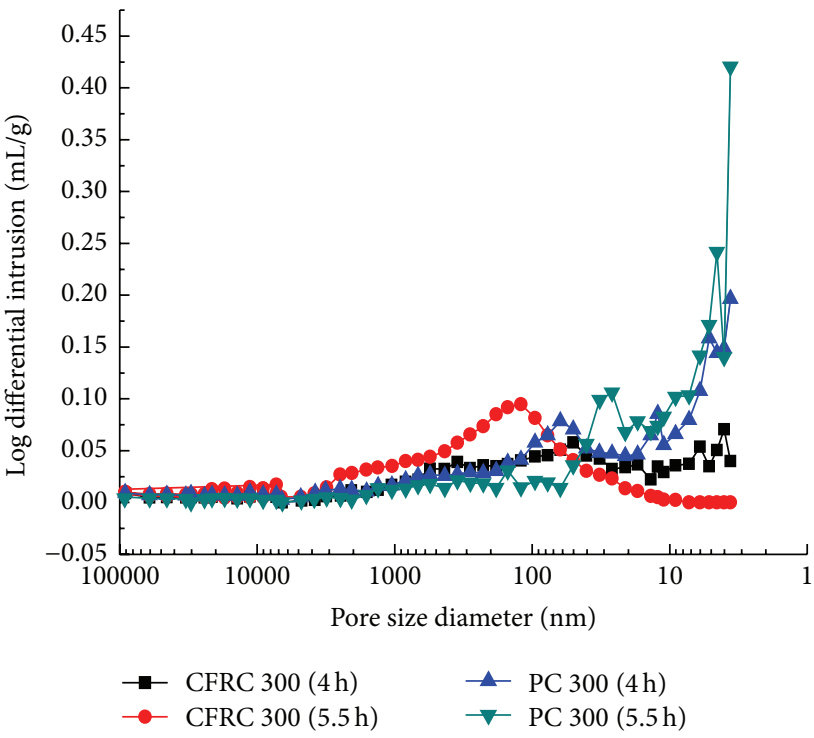

(b)

FIGURE 15: Pore size distributions of CFRC and PC after heating at $300^{\circ} \mathrm{C}$ for different holding times.

porosity is $5 \%$ at $20^{\circ} \mathrm{C}, 20 \%$ at $300^{\circ} \mathrm{C}, 25 \%$ at $600^{\circ} \mathrm{C}$, and $30 \%$ at $800^{\circ} \mathrm{C}$. Similarly, the porosities of heated PCs are always 10 to $15 \%$ greater than those of CFRCs at the same temperature. The pore size distributions of CFRCs and PCs at $300^{\circ} \mathrm{C}$ and $600^{\circ} \mathrm{C}$ are similar to those cured at $20^{\circ} \mathrm{C}$, but the number of pores smaller than $100 \mathrm{~nm}$ also becomes higher at these temperatures. Because the PC samples were totally decomposed to nonbinding dusts above $600^{\circ} \mathrm{C}$, only pore information for CFRC is presented at these temperatures. After heating at $1050^{\circ} \mathrm{C}$ for $4 \mathrm{~h}$, the CFRC porosity dramatically increased to
$45 \%$, owing to the creation of a greater number of pores larger than $100 \mathrm{~nm}$.

The influence of temperature on the porosities of the four categories of pores is summarized in Figure 18. For the PC specimens, the numbers of dangerous and highly dangerous pores dramatically increase at $300^{\circ} \mathrm{C}$. In contrast, these dangerous pores in CFRCs only obviously increase at $600^{\circ} \mathrm{C}$. This microstructural evolution is consistent with the degradation of mechanical behavior for PC and CFRC, as presented in Table 5. 


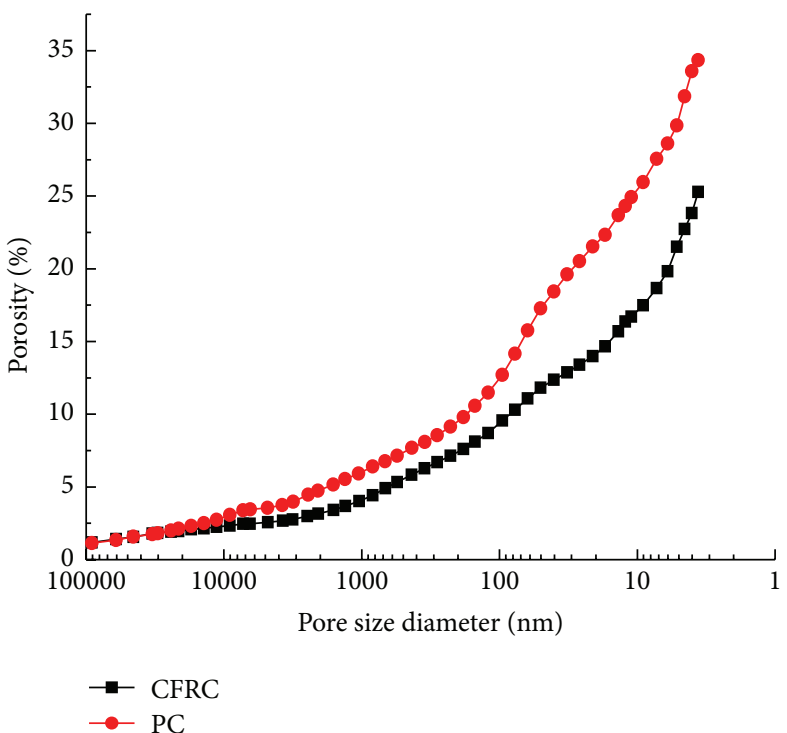

(a)

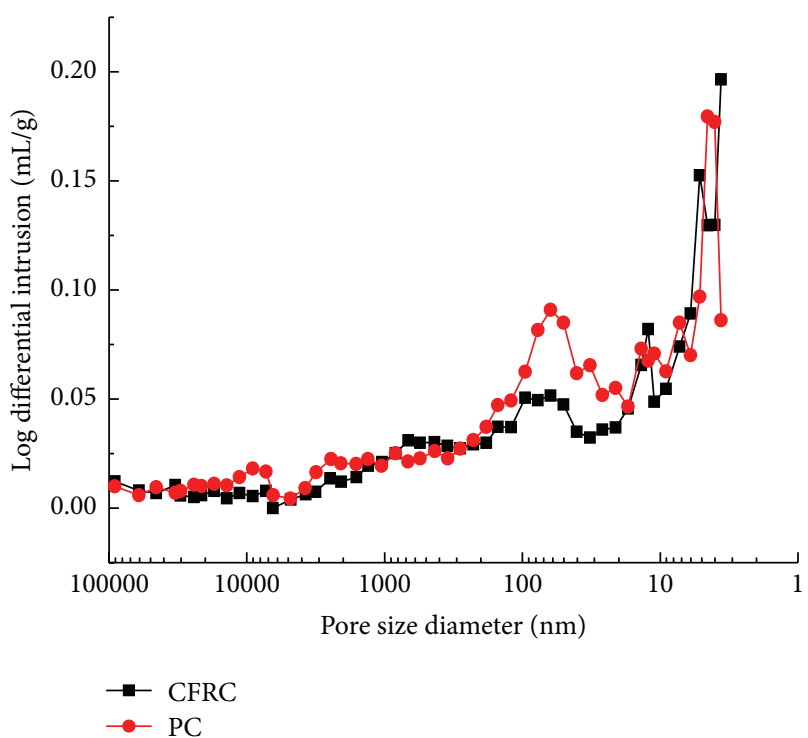

(b)

FIGURE 16: Pore size distributions of CFRC and PC after heating at $600^{\circ} \mathrm{C}$ for $4 \mathrm{~h}$.

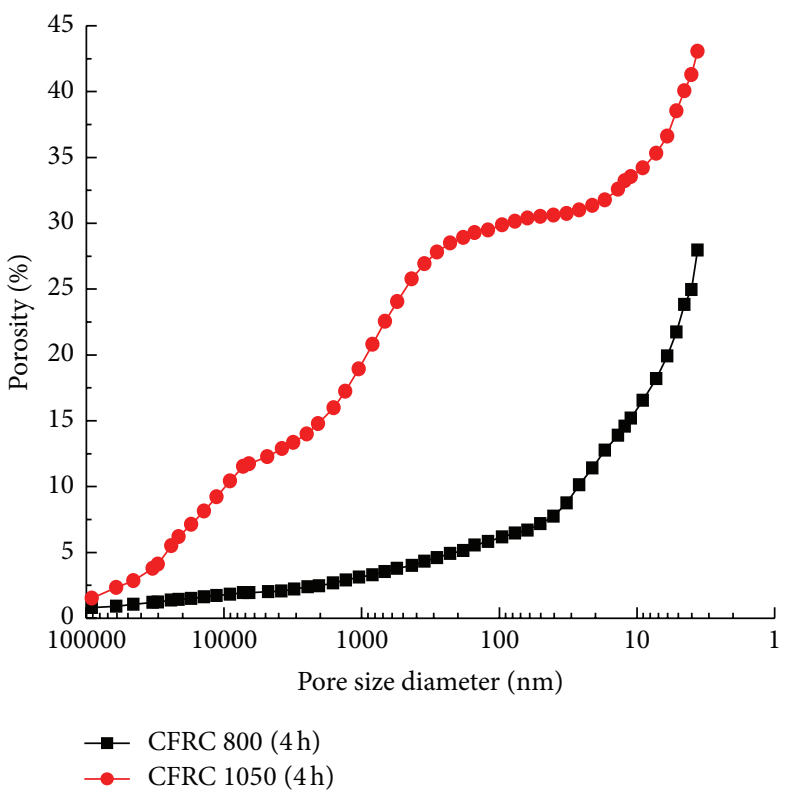

(a)

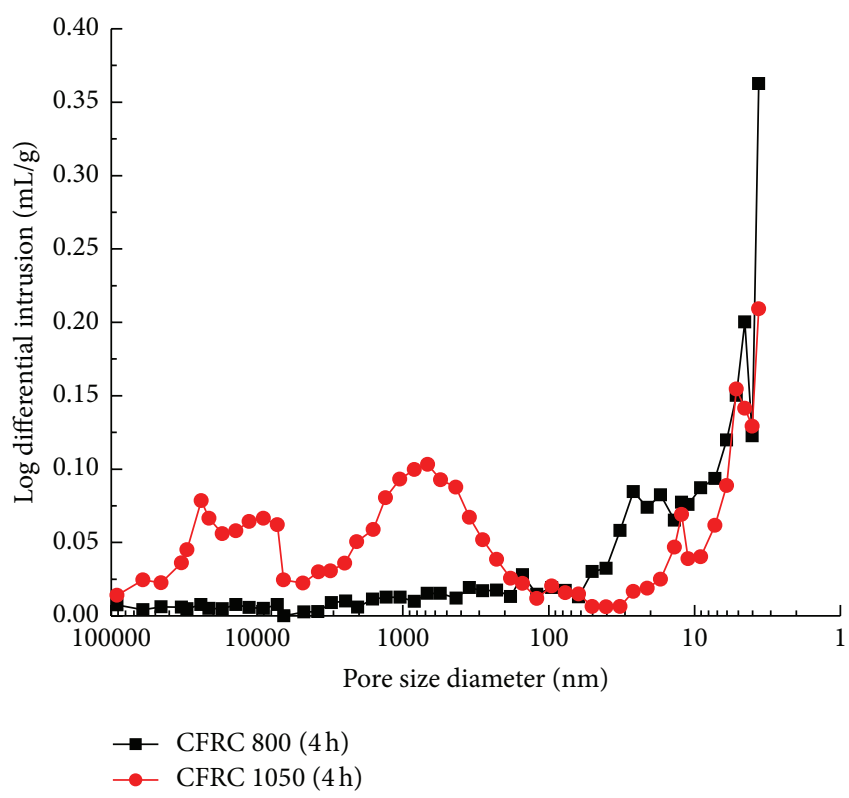

(b)

FIGURE 17: Pore size distributions of CFRC after heating at $800^{\circ} \mathrm{C}$ and $1050^{\circ} \mathrm{C}$ for $4 \mathrm{~h}$.

4.3. Thermal Analysis and Component Transformation. Thermogravimetric analysis was conducted to support the explanation of shrinkage and fusion of $\mathrm{CF}$ at high temperatures. As shown in Figure 19, it is clear that there are two peaks shown in the DSC spectrum. The first peak appears below $105^{\circ} \mathrm{C}$ owing to evaporation of absorbed water, while the second peak at $328^{\circ} \mathrm{C}$ is the temperature at which the CF itself is fused and decomposed. This coincides with a mass loss of $74 \%$, which explains the suddenly degraded mechanical properties of CFRCs heated above $300^{\circ} \mathrm{C}$.
To explain the degradation process of PC microstructures exposed to high temperatures, the thermal decomposition spectrum of the main hydrates in the CFRC matrix was also measured, as shown in Figure 20. The phase transformations of the main cement hydrates in the CFRC matrix were also quantitatively detected by XRD, as shown in Figure 21. The DSC spectrum is composed of five peaks: the first peak (below $105^{\circ} \mathrm{C}$ ) is ascribed to the evaporation of absorbed free water; the second peak $\left(105-139.5^{\circ} \mathrm{C}\right)$ represents the dehydration of ettringite (AFt) and $\mathrm{C}-\mathrm{S}-\mathrm{H}$ gel; the third peak 


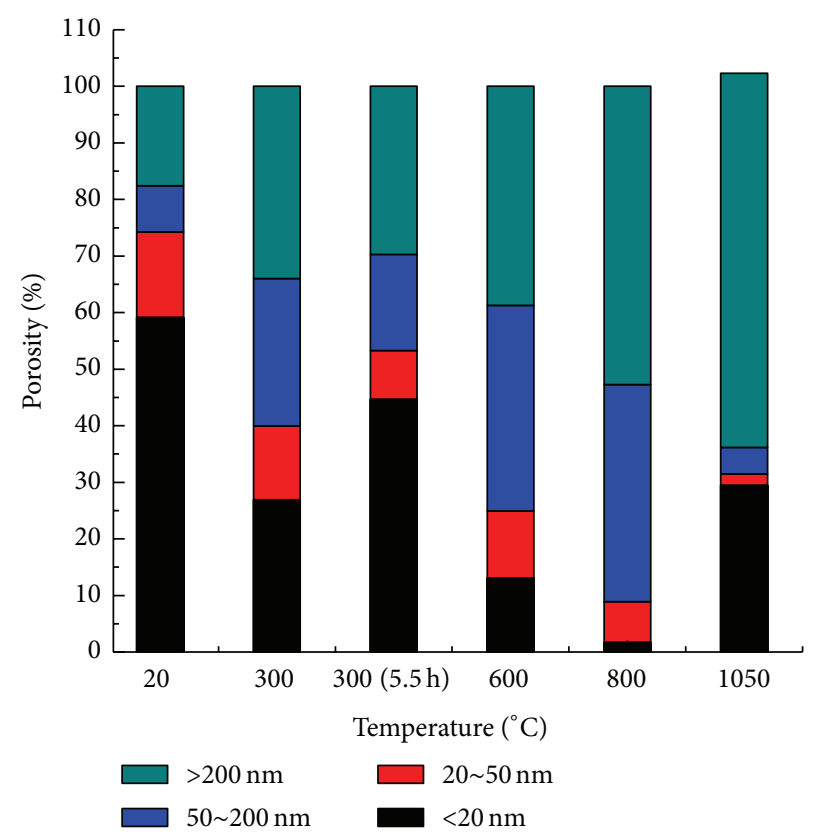

(a) CFRC

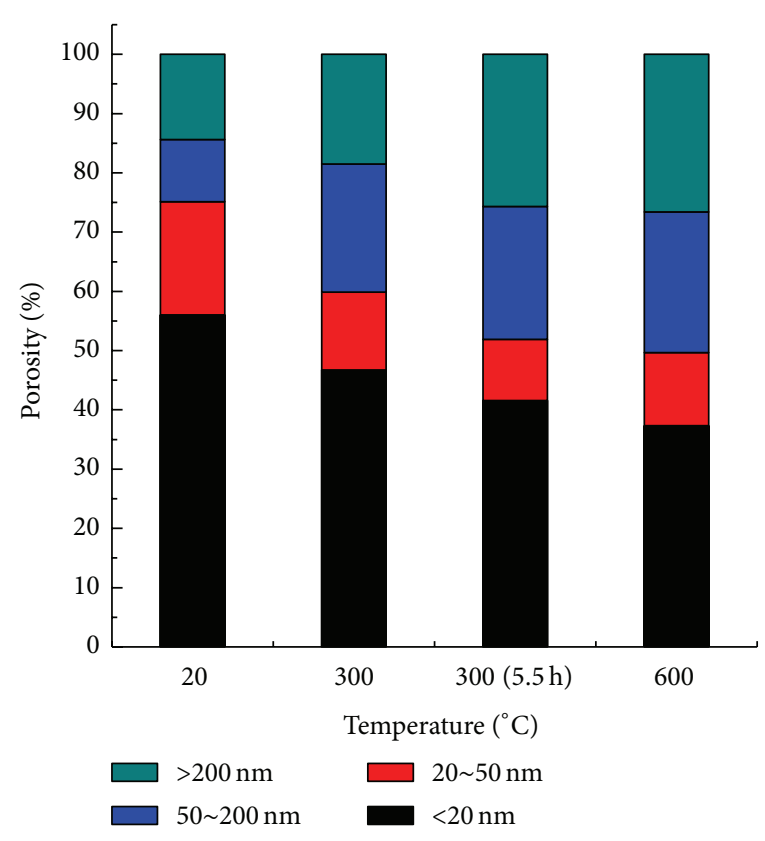

(b) PC

FIGURE 18: Influence of temperature on pore size in CFRC and PC samples.

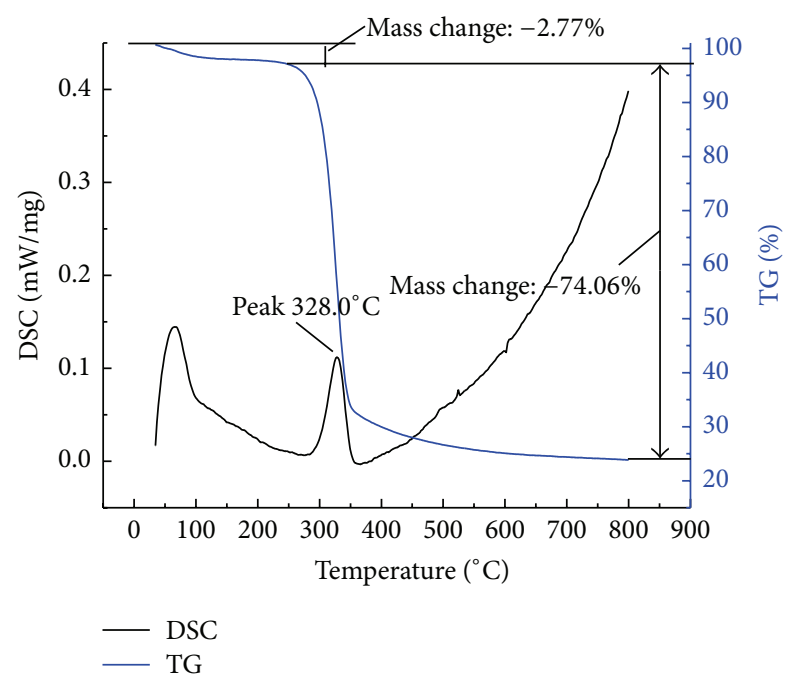

FIGURE 19: Thermal analysis spectrum of CF.

$\left(404.5-439.5^{\circ} \mathrm{C}\right)$ is due to the dehydration of $\mathrm{CH}$; the fourth peak $\left(739.5-794.5^{\circ} \mathrm{C}\right)$ is due to the decomposition $\mathrm{CaCO}_{3}$ and its transformation to $\mathrm{CaO}$; and the fifth peak (900$1050^{\circ} \mathrm{C}$ ) is attributed to the decomposition of $\mathrm{C}-\mathrm{S}-\mathrm{H}$ gel and its alternative transformation to anorthite and kyanite. The damage in the PC microstructures obviously accumulates at these temperatures, as shown in Figures 8 and 10.

In summary, $\mathrm{CF}$ is a novel internal-curing fiber that positively improves burst and spalling resistance of concrete exposed to high temperatures for different holding times. Performance degradation of CFRC results from CF fusion and the decomposition of hydrates when exposed to high

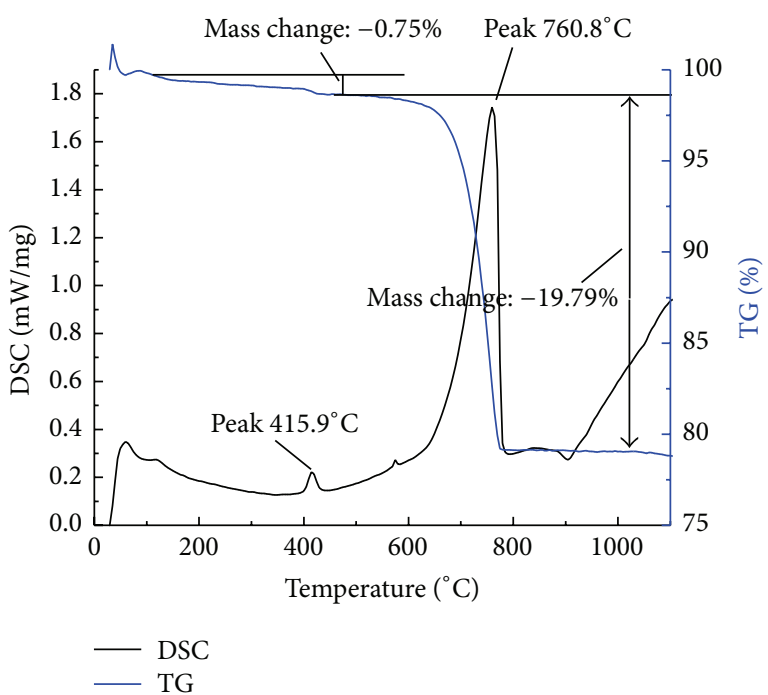

FIGURE 20: Thermal analysis spectrum of hardened cement paste in CFRC.

temperatures, based on the above data from a variety of experimental techniques. When temperature is below the fusion point of CF, all absorbed free water is extracted outside to promote hydration, thereby increasing the density of the CFRC matrix. Meanwhile, the CFs shrink because of water loss and significant volumes of micro porosity remain for dissipating the steam pressure without strength loss of the CFRC. At $600^{\circ} \mathrm{C}$, the microstructural degradation obviously and significantly weakens the bearing capacity of CFRC: the CFs fuse and leave thousands of nonconnected micropores, hydrated $\mathrm{CH}$ dehydrate, and $\mathrm{C}-\mathrm{S}-\mathrm{H}$ gels become 


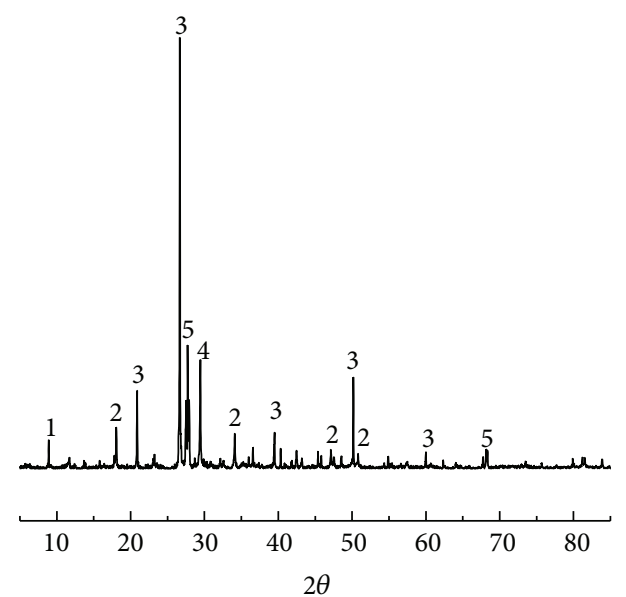

1: AFt 2: Portlandize 3: Quartz

4: Calcite

5: CSH-Ca ${ }_{4.5} \mathrm{Si}_{6} \mathrm{O}_{15}(\mathrm{OH})_{3} \cdot 2 \mathrm{H}_{2} \mathrm{O}$

(a)

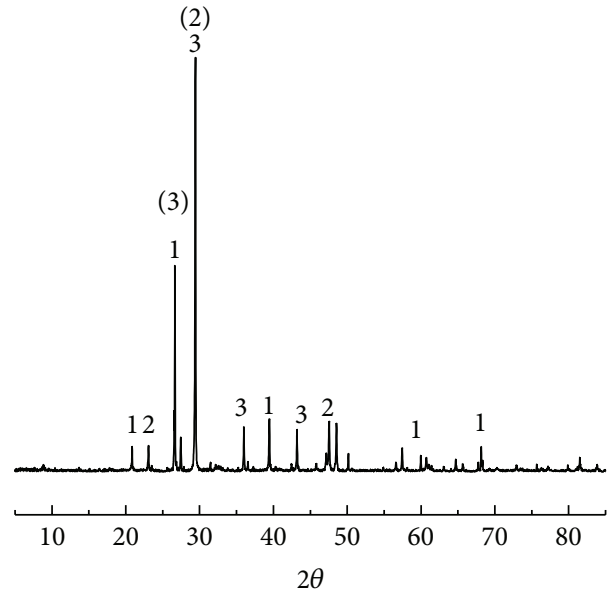

1: Quartz

2: Calcite

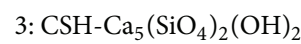

(c)

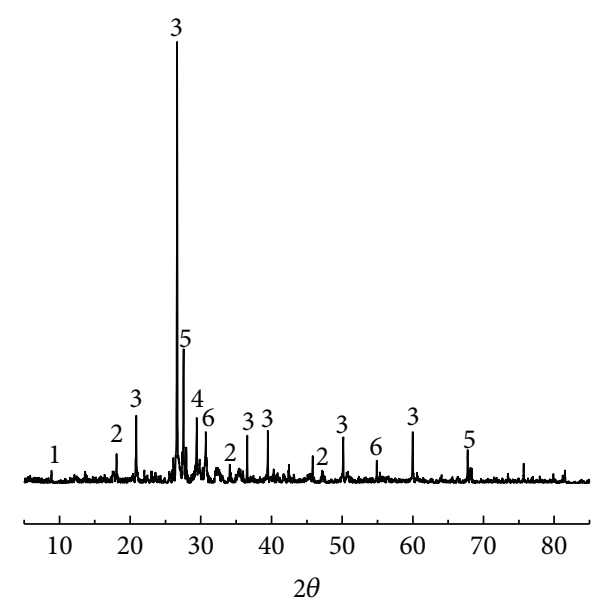

1: AFt
2: Portlandize
3: Quartz

4: Calcite

5: $\mathrm{CSH}-\mathrm{Ca}_{4.5} \mathrm{Si}_{6} \mathrm{O}_{15}(\mathrm{OH})_{3} \cdot 2 \mathrm{H}_{2} \mathrm{O}$ 6: $\mathrm{CSH}-\mathrm{Ca}_{5}\left(\mathrm{SiO}_{4}\right)_{2}(\mathrm{OH})_{2}$

(b)

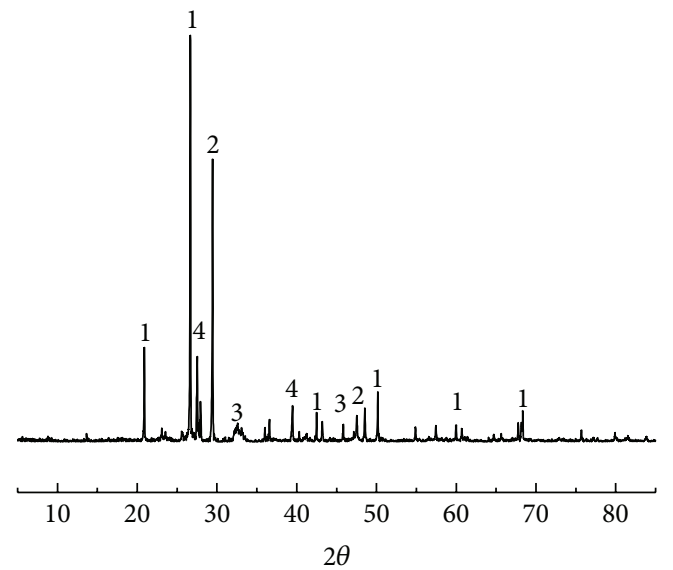

1: Quartz

2: Calcite

3: $\mathrm{CSH}-\mathrm{Ca}_{5}\left(\mathrm{SiO}_{4}\right)_{2}(\mathrm{OH})_{2}$ 4: $\mathrm{Ca}_{2} \mathrm{SiO}_{4}$

(d)

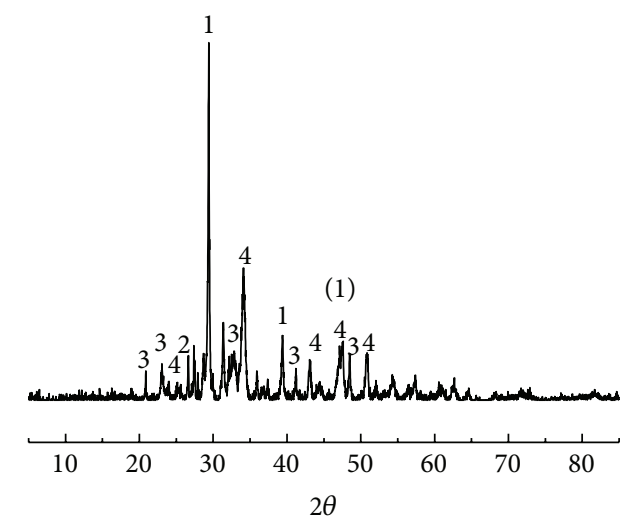

$\begin{array}{ll}\text { 1: } \mathrm{CaO} & \text { 3: kyanite } \\ \text { 2: Quartz } & \text { 4: anorthite }\end{array}$

(e)

FIGURE 21: XRD spectrums of CFRC matrix exposed to different temperatures. (a) $20^{\circ} \mathrm{C}$; (b) $300^{\circ} \mathrm{C}, 4 \mathrm{~h}$; (c) $600^{\circ} \mathrm{C}, 4 \mathrm{~h}$; (d) $800^{\circ} \mathrm{C}, 4 \mathrm{~h}$; (e) $1050^{\circ} \mathrm{C}, 4 \mathrm{~h}$. 
smaller separated phases with weak cementation capacity. After heating at $800^{\circ} \mathrm{C}$, the $\mathrm{C}-\mathrm{S}-\mathrm{H}$ gels further dehydrate and $\mathrm{CaCO}_{3}$ totally decomposes. Microcracks generated become connected nets and dramatically weaken the bearing capacity of CFRC without spalling or bursting. When the temperature exceeds $1000^{\circ} \mathrm{C}$, the $\mathrm{C}-\mathrm{S}-\mathrm{H}$ gels totally decompose and are transformed to anorthite and kyanite. In addition, large crack networks appear on the surface of the CFRC specimens and the bearing capacity of the CFRC is totally lost, but without causing bursting as well.

\section{Conclusions}

(1) The internal connected hollow structure of the employed CF is quantitatively evident for the first time by LSCM and FESEM, which makes CF not only of benefit for microcrack resistance, but also helpful for the long-term internal curing of CFRCs.

(2) The residual physical (e.g., mass loss ratio and relative elastic modulus) and mechanical properties (e.g., residual compressive strength and residual splitting tensile strength) of CFRCs are always better than those of PCs after being heated at different temperatures for various holding times. Degradation of CFRC properties only becomes evident when the temperature exceeds the fusion point of $\mathrm{CF}$.

(3) Owing to the original internal hollow structure and the remaining fused pores of CF that enable the gradual dissipation of the steam pressure and uneven thermal expansion, the rate of CFRC degradation is slowed down. The spalling resistance and loadbearing capacity of CFRC are outstanding compared with those of PC.

\section{Conflict of Interests}

The authors declare that there is no conflict of interests regarding the publication of this paper.

\section{Acknowledgments}

This work was supported by an open research fund of the Key Laboratory of Water Science and Water Engineering of Water Resources Ministry (Grant no. Yk914009) and partly supported by the key research fund of China Railway Corporation (Grant no. 2014G004-N) and the research project of the National Natural Science Foundation of China (Grant no. 51378113).

\section{References}

[1] W. X. Zhang, Study on durability, high temperature performance and creep of cellulous fiber reinforced concrete [M.S. thesis], Southeast University, Nanjing, China, 2015.

[2] L. Guo, W. Sun, Q. Cao, and J. Zong, "Study on optimized mixproportion and crack resistance of modern secondary lining concrete for high-speed railway tunnel," Advanced Materials Research, vol. 168-170, pp. 106-110, 2011.
[3] Q. Y. Cao, W. Sun, L. P. Guo, and G. R. Zhang, "Polymer-modified concrete with improved flexural toughness and mechanism analysis," Journal of Wuhan University of Technology (Materials Science Edition), vol. 27, no. 3, pp. 597-601, 2012.

[4] C. C. Hwang and J. D. Wargo, "Experimental study of thermally generated reverse stratified layers in a fire tunnel," Combustion and Flame, vol. 66, no. 2, pp. 171-180, 1986.

[5] L. H. Cheng, T. H. Ueng, and C. W. Liu, "Simulation of ventilation and fire in the underground facilities," Fire Safety Journal, vol. 36, no. 6, pp. 597-619, 2001.

[6] A. H. Akca and N. Ö. Zihnioğlu, "High performance concrete under elevated temperatures," Construction and Building Materials, vol. 44, no. 7, pp. 317-328, 2013.

[7] O. Düğenci, T. Haktanir, and F. Altun, "Experimental research for the effect of high temperature on the mechanical properties of steel fiber-reinforced concrete," Construction and Building Materials, vol. 75, pp. 82-88, 2015.

[8] S. Yang, D. Gao, and J. Zhao, "Microstructure of fiber reinforced concrete with slag power after effect of high temperatures," Journal of Southeast University, vol. 40, no. 2, pp. 102-106, 2010. 

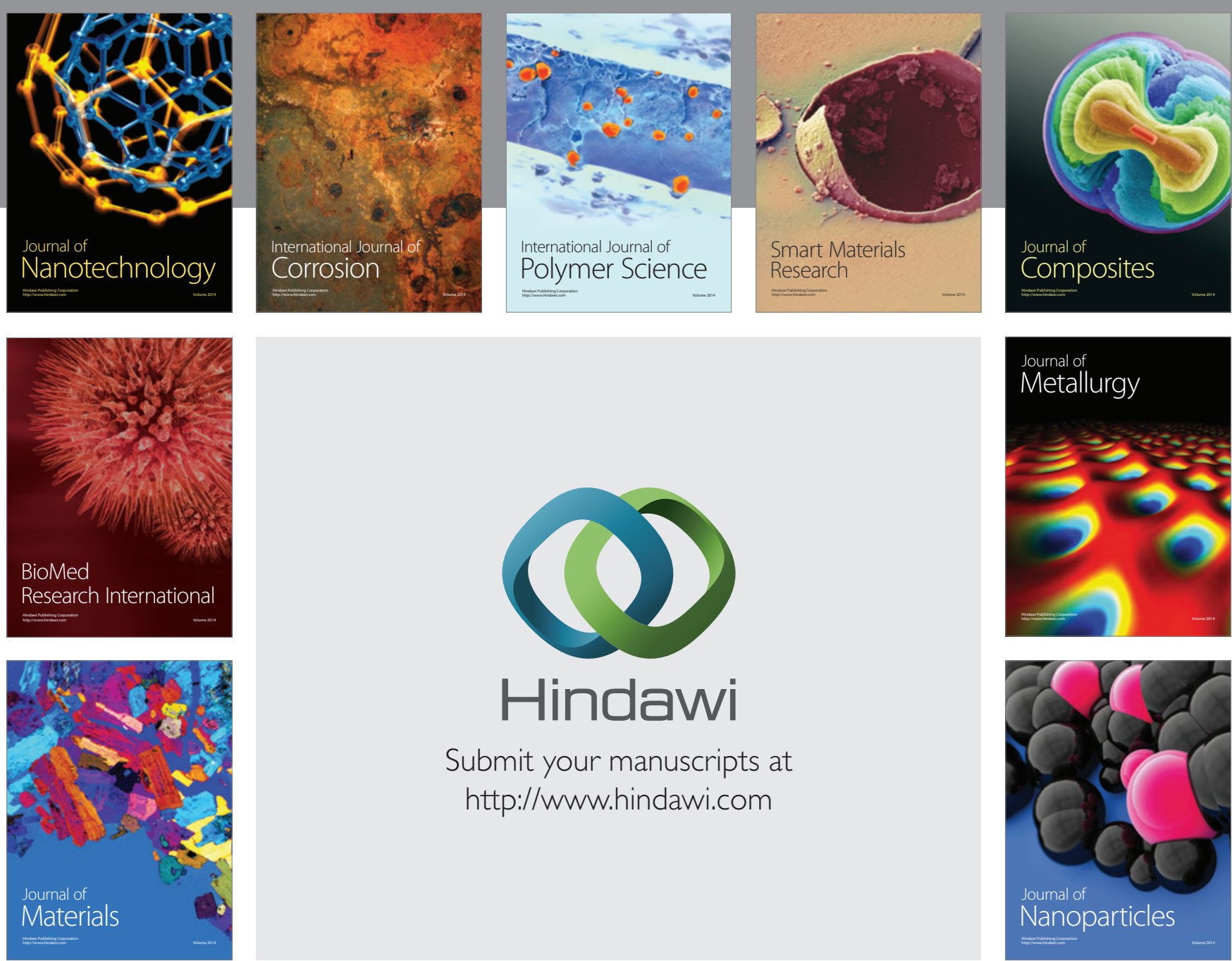

\section{Hindawi}

Submit your manuscripts at

http://www.hindawi.com

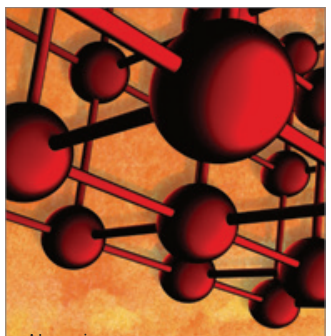

Materials Science and Engineering
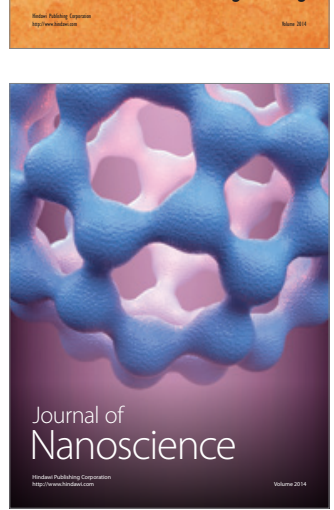
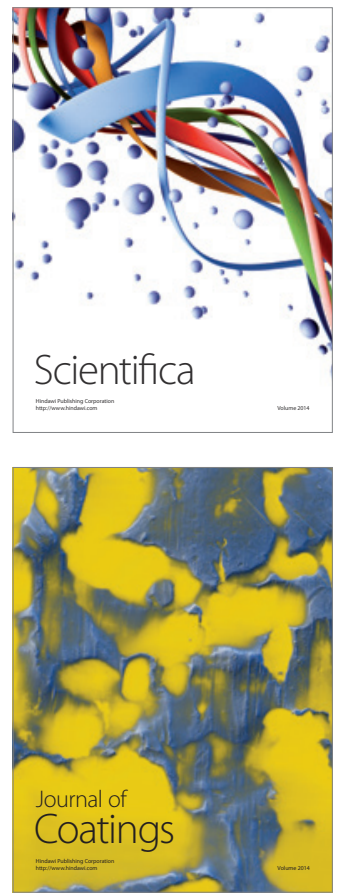
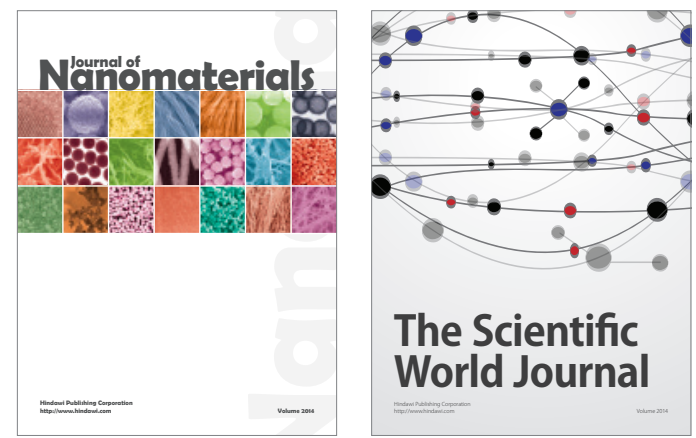

The Scientific World Journal
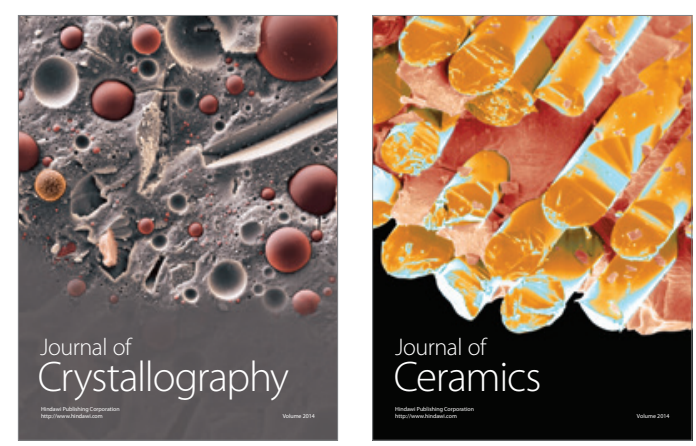
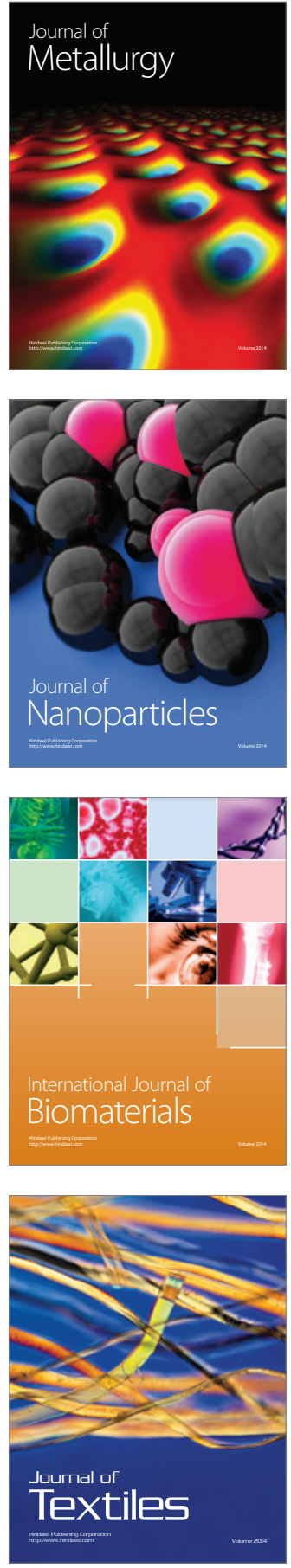